and purpose of development have changed, and the conception now gaining acceptance includes as an essential feature the improvement of the daily life of the people of the area concerned, whatever the other objects. While development should aim at maximum returns for minimum real cost and with no avoidable destruction of natural resources, increase of physical destruction is not desirable for its own sake but as a means of increasing the well-being of individuals. Long-term development, moreover, is only possible when there is enough determination within the country to push it through and meet and overcome opposition. This can only be secured by leadership within the country to be developed, and while outside agencies or governments will look for this leadership when they are deciding whether to participate in the country's schemes, this factor is one to be weighed by the country's government in selecting from the formidable total of projects that cannot be left to private initiative those to which the resources of the government and also of public authorities can be effectively committed without becoming unwieldy.

The selection of projects, in the view of Political and Economic Planning, has two aspects : choice of projects which make a genuine contribution to wellbeing, and ultimate selection of those which make the greatest contribution at the least real cost. An adequate survey of the resources, needs and possibilities of an area is an essential safeguard against disappointment and failure; but, even so, there will often be in practice difficult options between benefits to different groups in a country or between a smaller benefit early as against a greater benefit later. Moreover, the many factors which should be considered as a single pattern in selecting projects should all be kept in mind at every stage of planning. The results of development and its costs must be interpreted widely, and the costs of upheaval set against the benefits of increased consumption or improved health. Alike in the selection and planning of projects and in their execution, the Broadsheet lays much stress on the human aspects of development. The aim should be, if possible, to make the process of development beneficial as well as the end result. Constructive work can be good in itself, and, in stressing the importance of securing co-operation and cultivating mutual respect, $\mathrm{PE} P$ is directing attention to the human and social problems of change which are as challenging and important as the technical difficulties and must be tackled with understanding and vision by whatever forms of organization or administration are established to further particular development projects.

\section{SCIENCE IN THE UNITED STATES}

$\mathrm{T}$

HE British Commonwealth Scientific Office (North America), which has been established in Washington, D.C., since the autumn of 1944, is the outcome of the scientific mission under the leadership of Sir Henry Tizard that was sent to Washington in 1940 to facilitate the exchange of scientific and technical information between the Governments of the United Kingdom and the United States. This mission continued throughout the Second World War, being known in turn as the British Technical Mission, the Central Scientific Office, the British Central Scientific Office, and (when, following the successive establishment of separate scientific offices in Washington by New Zealand, Australia and, finally, in September 1944, Canada, the British Commonwealth Scientific Office was established) the United Kingdom Scientific Mission. When the British Commonwealth Scientific Conference met in London in 1946, the value of the Office was already recognized, and the Governments concerned were asked to make suitable arrangements for its continuance as a necessary element in the permanent machinery for scientific liaison. About this time, moreover, the emphasis in the work of the Office was changing from military applications to scientific problems arising from the particular economic and industrial needs experienced by each Mission's own country. The Missions still found, however, that they shared many interests and that the collaboration built up during the War could be profitably continued.

The Office now includes the United Kingdom Scientific Mission and Liaison Offices for Canada, Australia, New Zealand and South Africa. Each Mission is independent and is responsible only to its own Government. 'They co-operate wherever it is to their mutual advantage, sharing office premises and services, but there is no director : the head of each Mission takes it in turn to act as chairman of a house committee which meets monthly and settles affairs of mutual interest and the operation of common services.

The development of the Office is described in the preface to the "BCSO Review of Science in U.S.A. for the Year ending June 1952", which has recently been published*. Although the first to be published, it is the fifth in a series of such annual reviews and brings together much information of interest to the scientist and technologist in Great Britain which is not always readily available or at best widely scattered. There are references to all the major reports dealing with research and development published in the United States during the year under review so that, as a guide to such source material and the comparison of trends in the United States and the United Kingdom, this review should be sure of a warm welcome, and it is to be hoped that its publication will be continued.

The review begins with a general analysis of the growth and distribution of research and development in the United States. During the past decade this has increased by about 270 per cent and, whereas in 1941 only about 7 per cent of the work in industrial and university laboratories received Federal support, in 1952 this figure is estimated at 39 per cent and the Federal Government now pays for 56 per cent of all United States research and development activities : for $1952-53$, this is estimated at 1,640 million dollars out of 2,930 million. Some 91,000 science and technology graduates, more than half of whom are engineers, are employed by the Federal Government, excluding those working on Government projects operated by outside bodies, and, of this total, 58,000 are estimated to be employed on research projects. Altogether some 71,000 professional persons are estimated to be employed in industrial research and development, together with 41,000 technical and 54,000 non-technical assistants.

Expenditure on research and development in the universities rose from 80 million dollars in 1941 to 280 millions in 1952 and is estimated at 350 millions for 1952-53, of which 90 per cent will be for research

* British Commonwealth Scientific office, North America. The Pp. iv +40. (London: H.M.S.O., 1953.) 2s. 6d. net. 
in the biological and physical sciences, including engineering, and 300 millions of this will come from the Federal Government. This dependence on Federal support as well as the bias towards science and technology is already disturbing educational authorities, who fear that the heavy bias towards applied science will also destroy the balance between applied and pure science in the universities and seriously affect the teaching staff of American universities. Some estimates of the research effort of American universities in terms of man-power are cited for the physical and engineering sciences and for medical research.

The next two sections of the survey summarize the findings of the Paley Commission and other bodies concerned with the conservation of materials, and the position of the National Science Foundation and the work of the Interdepartmental Committee on Scientific Research and Development. There follows a series of brief reports on progress in atomic energy and nuclear physics; building research and techniques; mechanical and production engineering; computing machines; water supply and treatment; chemistry; metallurgy; fuel and power; and the biochemistry of food processing and preservation. Finally, the technical assistance programme of the Mutual Security Agency is described, although with this only the United Kingdom Scientific Mission is concerned. Among new developments referred to in this report are mortars made with polyvinyl acetate emulsions, a new brick, a method by which concrete slabs for upper floors or flat roofs can be cast at ground-level and jacked into position, a novel lathecutting tool, a "permionic membrane" for giving potable water from brackish or sea water, a continuous ion-exchange process designed by the Stanford Research Institute, the introduction of butadienestyrene latex-based paints and the rapidly increasing use of antibiotics in feeding farm animals.

\section{BRITISH COLONIAL WELFARE AND DEVELOPMENT DURING 1952-53}

A

GLANCE at the "Return of Schemes" made under the Colonial Development and Welfare Acts by the Secretary of State for the Colonies during the period April 1, 1952-March 31, 1953 (Colonial Paper 189. Pp. 26. London: H.M.S.O., June 1953; $1 s .3 d$.$) , reveals the dependence of Colonial research on$ the funds provided under these Acts and the importance of the legislation contemplated in the 1954-55 session to which the Colonial Secretary, Mr. Oliver Lyttelton, referred in his statement to the House of Commons on June 24. The schemes detailed in the White Paper bring the total commitments for development and welfare schemes under the Acts to $£ 97,662,196$, of which $£ 13,889,622$ is for the year in question, and for research schemes to $£ 11,710,492$, of which $£ 1,087,041$ is for the year ended. March 31, 1953 . Of this, $£ 372,486$ is for agriculture, $£ 204,878$ for medicine, $£ 204,143$ for insecticides, $£ 119,115$ for products research $(£ 41,600$ of which goes to the Colonial Products Research Council), $£ 47,804$ for fisheries, $£ 37,754$ for economic research, $£ 31,330$ for locust control, $£ 23,293$ for tsetse and trypanosomiasis, and $£ 24,088$ for social science.

Of the actual research schemes, the largest are

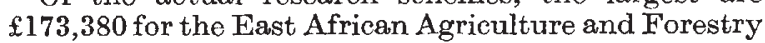

Research Organization, $£ 90,000$ for the East African Insecticides Research Unit, $£ 106,597$ for the Medical Research Council's Field Research Station at Fajara, Gambia, and $£ 77,515$ for the Colonial Microbiological

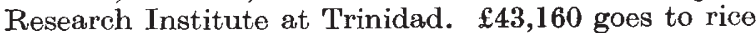
research in Nigeria, $£ 43,000$ to the East African Fisheries Research Organization, $£ 32,935$ to the establishment of an Agricultural Research and Experimental Station in Nyasaland, $£ 31,330$ to the maintenance of the Anti-Locust Research Centre and its extra-mural work, $\mathfrak{2} 29,321$ to the East African Institute of Social and Economic Research, $£ 26,450$ to the Hot Climate Physiology Unit in Nigeria, $£ 24,000$ to malaria research in Trinidad, $£ 19,200$ for research into the control of Stomoxys calcitrans in Uganda, and $£ 16,900$ for fundamental insecticide research at the Silwood Park Station (Imperial College of Science and Technology, London) and at, Rothamsted Experimental Station.

Grants of particular scientific interest for development and welfare schemes, apart from those for geodetic, topographical, geological and mineral surveys, include $£ 29,476$ for the control of 'sudden death' disease of cloves in Zanzibar, $£ 185,000$ for a scholarship scheme for residents in Colonial territories to provide training to qualify for public service, $£ 121,620$ to University College, Ibadan, $£ 108,040$ for the development of African education, and substantial grants for the improvement or development of roads in Nyasaland ( $£ 220,000$ ), Malta ( $£ 364,394)$, North Borneo $(£ 305,900)$ and British Guiana $(£ 315,416)$, and for the improvement of water supply or control in British Guiana $(£ 919,481)$, the Gold Coast $(£ 488,000)$, Malta $(£ 320,250)$ and Gambia $(£ 70,000)$. Of a further $£ 1,230,000$ for the Uganda Development Plan, $£ 180,000$ is for geology and rural water supplies, $£ 390,000$ for education, $£ 120,000$ for medical schemes, $£ 150,000$ for urban water supplies and $£ 90,000$ for agriculture.

\section{UNIVERSITIES' COUNCIL FOR ADULT EDUCATION REPORT FOR $1951-52$}

YNLIKE the previous six annual reports of the Universities' Council for Adult Education, the seventh annual report, covering the year 1951-52, attempts to survey the extra-mural work of the constituent universities as a whole*. During the year, the work of University Extra-mural Departments throughout Great Britain further expanded, and the departments in the Council became more closely associated. With the addition of the Universities of Edinburgh, Glasgow and Belfast, the membership of the Council is now twenty-one, and the number of courses and classes conducted was 4,064, as compared with eighteen and 2,067, respectively, during 194546. During the 1951-52 session, two committees completed their investigations into the teaching of science and the training of teachers, respectively, while the up-to-date bibliography of adult education and the handlist of current studies in the subject, prepared by the Council's Research and Training Sub-Committee, were published, as a co-operative enterprise, by the National Institute of Adult Education.

* Universities Council for Adult Education. Report on the Year 1591-1952. Pp. 26. (Bristol: W. E. Salt, Hon. Secretary, The University, Bristol, 1953.) n.p. 